\title{
Spinal intradural mature teratoma in an elderly patient
}

\author{
Atef Ben Nsir ${ }^{1}$, Karim Ben Hammouda², Imed Ben Said², Alia Zhani Kassar ${ }^{3}$, Nidhameddine Kchir ${ }^{3}$, Hafedh Jemel ${ }^{2}$ \\ ${ }^{I}$ Department of Neurological Surgery, Fattouma Bourguiba University Hospital, University of Medicine of Monastir, Monastir 5000, Tunisia. \\ ${ }^{2}$ Department of Neurological Surgery, Tunisian National Institute of Neurology, University of Medicine of Tunis El Manar, Tunis 1007, Tunisia. \\ ${ }^{3}$ Department of Pathology, La Rabta University Hospital, University of Medicine Tunis El Manar, Tunis 1007, Tunisia.
}

Correspondence to: Dr. Atef Ben Nsir, Department of Neurological Surgery, Fattouma Bourguiba University Hospital, University of Medicine of Monastir, Monastir 5000, Tunisia. E-mail: atefbn@hotmail.fr

\section{A B S T R A C T}

Spinal intradural mature teratomas are rarely encountered in adults. In this report, one of the oldest patients ever reported to harbor an intradural mature teratoma of the conus medullaris is presented, and the relevant literature concerning the teratoma's origin, clinical presentation, radiological features, and treatment modalities is reviewed. A previously healthy 70 -year-old woman presented with a 2-month history of left sciatica. Her neurological examination was normal and the magnetic resonance imaging of the thoracolumbar spine showed an intradural, partially cystic mass extending from T12 to L3 level. The patient underwent a T11-L4 laminectomy. After opening the dura, a yellowish vascular tumor attached to the conus medullaris came into view. Meticulous dissection allowed for subtotal tumor removal. Only a thin part of the tumor wall, tightly attached to the conus medullaris, was left. The tumor was diagnosed as mature teratoma by histological study, and no adjunctive therapy was administered. The pain experienced by the patient disappeared postoperatively. Her condition remained unchanged with no radiological recurrence through the most recent follow-up examination, 3 years after surgery. The present study outlines that mature teratoma can arise from the conus medullaris, even in older adult patients. Functional preservation is of utmost importance, and long-term follow-up is mandatory to spot recurrences early.

Key words: Conus medullaris tumor, mature teratoma, surgery

\section{Introduction}

In 1863, an unprecedented finding, Rudolf Virchow described the "Krankenhaften Geschwülst," an intraspinal "monstrous tumor" better known today as teratoma. One hundred and fifty years later, the origin, natural history, and occurrence of teratoma in elderly individuals are still subjects of debate. Spinal teratoma is, in fact, an extremely rare entity representing only $0.1-0.6 \%$ of all spinal tumors ${ }^{[1]}$ and mainly diagnosed during the first two decades of life. With only 31 described cases, adult forms are most uncommon. This report contributes to the understanding of these rare tumors by presenting an exceptional case of a conus medullaris mature teratoma in a 70-year-old woman and reviewing the relevant literature concerning its origin, clinical characteristics, radiological features, and treatment modalities.

\section{Case Report}

A previously healthy 70-year-old woman presented to our department in July 2011 with a 2-month history of left sciatica, with progressive aggravation. On admission,

\begin{tabular}{|l|l|}
\hline \multicolumn{2}{|c|}{ Access this article online } \\
\hline Quick Response Code: & Website: \\
\hline & www.jcmtjournal.com \\
\cline { 2 - 2 } & \\
\hline
\end{tabular}

her neurological examination was unremarkable and the physical examination including detailed clinical examination of the trunk and the extremities, did not find any patchy area of abnormal hair or dimple on her back. Anteroposterior and lateral radiographs were normal, and spinal magnetic resonance imaging confirmed the presence of a partially cystic and enhancing intradural lesion extending from T12 to L3 level [Figure 1].

A T12-L4 laminectomy was performed. The dura was opened in the midline, and a yellowish, vascular tumor came into view. The tumor originated from the conus medullaris and developed freely between the nerve roots. Fatty substance was present outside the tumor, and mucous substance, bony fragments, and hair were found inside the tumor.

Curettage of the cystic content was performed and progressive dissection allowed for a subtotal resection. A thin rim of the capsule that was tightly adherent to the conus medullaris was left. This was considered safer than performing a radical resection that would probably lead to a severe neurological deficit. The patient improved remarkably postoperatively. Her pain disappeared immediately. Histological examination showed a large number of glandular formations covered by mature, prismatic, and flattened cubic epithelial cells. These structures were embedded between fibrovascular tissue and mature fat tissue, which included some cystic formations. Three germ cell layers (including ectodermal, mesodermal, and endodermal elements) 
were observed, and the final histological diagnosis was mature teratoma [Figure 2]. No adjunctive therapy was administered. The patient has shown no clinical or radiological sign of progression through the most recent follow-up examination, 3 years after surgery [Figure 3].

\section{Discussion}

Teratoma is one of the rarest intraspinal neoplasms, representing $0.1-0.6 \%$ of all spinal tumors. ${ }^{[1]}$ It typically affects young individuals in their first or second decade of life and is frequently associated with spinal dysraphic defects. Adult cases are exceptional. Their rarity and the use of various terms to describe them led to limitations in understanding of the disorder and speculation about their true origin and natural history. We searched the PubMed and Medline databases for adult intradural mature teratomas and present here a comprehensive review of the literature concerning these rare tumors.

The total number of adult spinal intradural mature teratomas reported to date is 31 . They are summarized in Table 1. The mean age at presentation was 36 years in men and 44 years in women, with a slight female predominance (sex ratio: 0.8). These lesions were predominantly located in the lower thoracic and thoracolumbar spine. Only five cases of conus medullaris mature teratoma were reported. ${ }^{[14-16,26,27]}$

The review indicates that, in sharp contrast to pediatric cases, adult cases typically presented with subtle, nonspecific symptoms like back pain or radiculopathy. Furthermore, although these patients commonly experienced a certain degree of neurological disorder, motor weakness was not always obvious. ${ }^{[30,31]}$ Associated dysraphism, commonly seen in young patients, was found in only 6 adult patients $(19 \%) .^{[3,5,13,14,21,22]}$

Radiologically, displaced pedicles, erosions, thinned laminae or calcifications on conventional X-rays are of significance and should be followed by a more extensive investigation. $^{[21]}$ However, as demonstrated in this case, these findings are not always present. Computed tomography provides an optimal assessment of bony structures, but it is of limited interest for the exploration of the spinal cord and the extent of the tumor.

Magnetic resonance imaging is regarded as the gold standard imaging technique because it best delineates the tumor characteristics and depicts the degree of spinal cord involvement. The morphological presentation varies according to the location of the tumor. Intradural teratomas are commonly oval or lobulated, heterogeneous masses. Cystic components are usually found in adult cases, which can lead to confusion with more common epidermoid and dermoid cysts. ${ }^{[17]}$

In the present case, a well-demarcated and strongly enhancing tumor was found, compounding the diagnostic challenges and highlighting the unspecific radiological aspect of spinal mature teratomas in
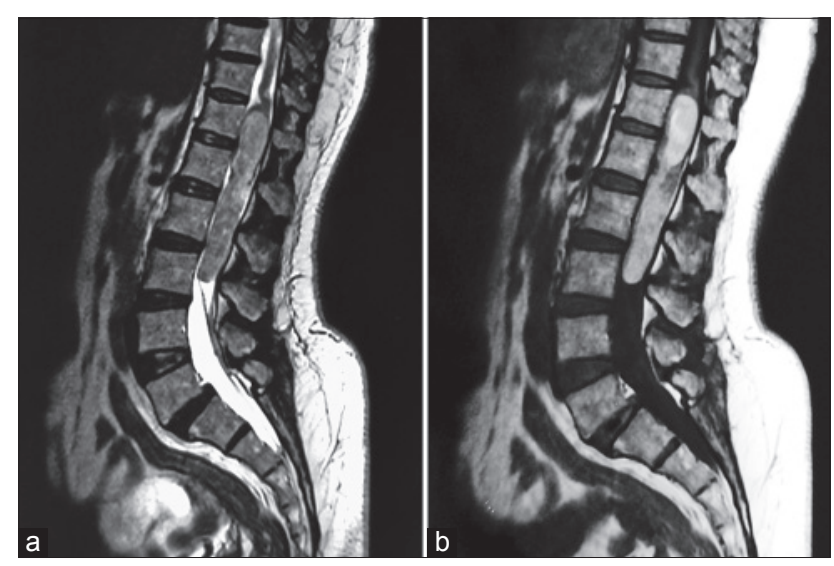

Figure 1: Sagittal T2-weighted (a) and T1-weighted post-gadolinium (b) magnetic resonance images showing a partially cystic and enhancing intradural mass located between T12 and L3 spinal levels

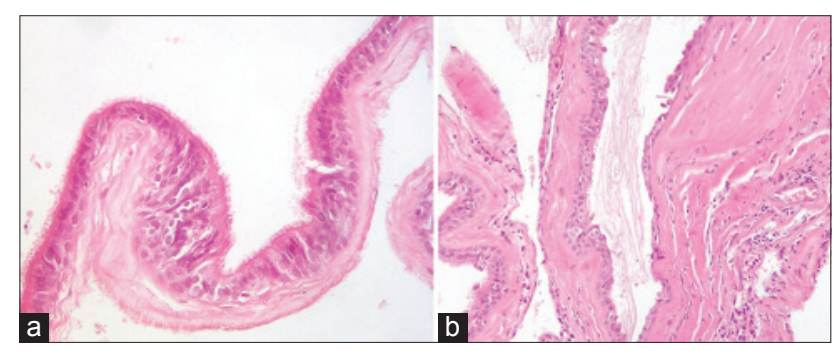

Figure 2: Photomicrographs of the tissue obtained intraoperatively. (a) A slightly disorganized cartilage surrounded by respiratory mucosa complete with bronchial glands and ciliated columnar epithelium (H and E, $\times 20$ ); (b) cystic formations covered by multiple levels of keratinous squamous epithelial cells containing keratin lamellae $(\mathrm{H}$ and $\mathrm{E}, \times 20)$. $\mathrm{H}$ and $\mathrm{E}$ : Hematoxylin and eosin stain

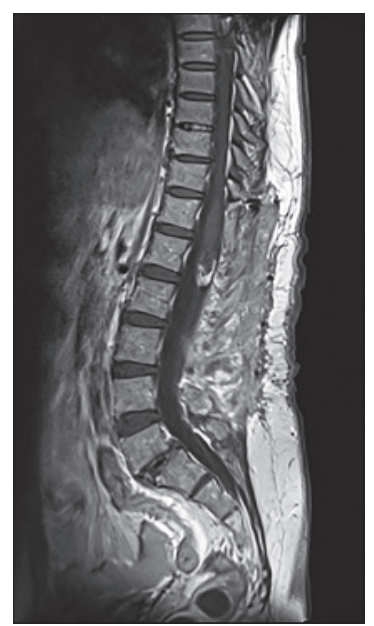

Figure 3: Sagittal T1-weighted post-gadolinium follow-up magnetic resonance imaging showing the stabilized tumor remnant at the conus medullaris level

elderly individuals. From the histological point of view, Russel and Rubinstein ${ }^{[32]}$ describe teratomas as tumors that contain a mixture of the three germinal layers of ectoderm, endoderm, and mesoderm. The review of the literature revealed that in a number of cases, only two of the three germinal layers were observable, perhaps because the derivatives of one or two of the layers may overgrow others. ${ }^{[10,19]}$ Spinal mature teratomas do not differ from extragonadal ones and are composed exclusively of fully differentiated "adult type" tissue 
Table 1: Adult intradural spinal mature teratoma cases previously reported in the literature

\begin{tabular}{|c|c|c|c|c|c|}
\hline Author, year & Age & Male/female & Spinal level & Associated dysraphism & Extent of surgery \\
\hline Kubie and Fulton, ${ }^{[2]} 1928$ & 27 & Female & $\mathrm{C} 3-\mathrm{C} 4$ & No & Incomplete \\
\hline Hosoi, ${ }^{[3]} 1931$ & 24 & Male & L2-L3 & L5-S1 spina bifida & Incomplete \\
\hline Sullivan, ${ }^{[4]} 1948$ & 32 & Female & L1-L3 & No & Complete \\
\hline Bakay, ${ }^{[5]} 1956$ & 65 & Female & L1-L2 & L1 and L2 vertebral body & Incomplete \\
\hline Sloof et al.,${ }^{[6]} 1964$ & 20 & Male & L1 & No & Complete \\
\hline Rewcastle and Francoeur, ${ }^{[7]} 1964$ & 34 & Female & $\mathrm{T} 10$ & No & Incomplete \\
\hline Hansebout and Bertrand, ${ }^{[8]} 1965$ & 47 & Male & L1-L3 & No & Complete \\
\hline Eneström and Von Essen, ${ }^{[9]} 1977$ & 36 & Male & T11-L1 & No & Incomplete \\
\hline Rosenbaum et al..${ }^{[10]} 1978$ & 49 & Male & T9 & No & Complete \\
\hline Garrison and Kasdon, ${ }^{[11]} 1980$ & 23 & Male & L2 & No & Complete \\
\hline Padovani et al.., ${ }^{[12]} 1983$ & 33 & Female & T12-L1 & No & Complete \\
\hline Pelissou-Guyotat et al.. ${ }^{[13]} 1988$ & 33 & Male & L4 & L4 spina bifida occulta & Complete \\
\hline Nicoletti et al., ${ }^{[14]} 1994$ & 47 & Male & Conus medullaris & Conus medullaris caudal exophy & Incomplete \\
\hline Caruso et al.., ${ }^{[15]} 1996$ & 41 & Male & Conus medullaris & No & Complete \\
\hline al-Sarraj et al., ${ }^{[16]} 1998$ & 35 & Male & Conus medullaris & No & Incomplete \\
\hline Poeze et al.. ${ }^{[17]} 1999$ & 23 & Male & T12-L1 & No & Incomplete \\
\hline Fan et al., ${ }^{[18]} 2001$ & 43 & Female & L2 & No & Complete \\
\hline \multirow[t]{2}{*}{ Nonomura et al., ${ }^{[19]} 2002$} & 37 & Female & T12-L1 & No & Incomplete \\
\hline & 56 & Male & T12-L2 & No & Incomplete \\
\hline \multirow[t]{2}{*}{ Hejazi and Witzmann, ${ }^{[20]} 2003$} & 45 & Female & T11-L3 & No & Complete \\
\hline & 20 & Male & L2-L4 & No & Complete \\
\hline Fernández-Cornejo et al., ${ }^{[1]} 2004$ & 43 & Male & L1-L2 & No & Complete \\
\hline Ak et al.,${ }^{[21]} 2006$ & 43 & Female & $\mathrm{C} 2-\mathrm{C} 3$ & C3 spinal bifida, C5 level nodule & Complete \\
\hline Makary et al.., ${ }^{[22]} 2007$ & 46 & Female & $\mathrm{C} 1-\mathrm{C} 2$ & $\begin{array}{l}\mathrm{C} 1-\mathrm{C} 2 \text { dysraphic congenital } \\
\text { spinal malformations }\end{array}$ & Complete \\
\hline Biswas et al., ${ }^{[23]} 2009$ & 28 & Male & L2-L4 & No & Complete \\
\hline Ghostine et al.., ${ }^{[24]} 2009$ & 65 & Female & $\mathrm{C} 1-\mathrm{C} 2$ & No & Incomplete \\
\hline Ijiri et al., ${ }^{[25]} 2009$ & 68 & Female & L1-L2 & No & Complete \\
\hline Jian et al., ${ }^{[26]} 2010$ & 57 & Male & Conus medullaris & No & Complete \\
\hline Musil et al., ${ }^{[27]} 2011$ & 60 & Female & Conus medullaris & No & Incomplete \\
\hline Li et al., ${ }^{[28]} 2013$ & 23 & Female & T12-L2 & No & Complete \\
\hline Vanguardia et al., ${ }^{[29]} 2014$ & 41 & Male & Cauda equina & No & Incomplete \\
\hline
\end{tabular}

elements. Because their capsule typically adheres to the spinal cord, radical removal carries a high risk of neurological deficits.

The pathogenesis of spinal intradural teratomas is still a subject of debate. The two widely held theories regarding the origin of intraspinal teratomas are the misplacement germ cell theory and the dysembryogenic theory. ${ }^{[7,16]}$ The traditional theory is the misplacement germ cell theory. It suggests that certain pluripotent primordial germ cells of the neural tube are misplaced during their migration to the gonadal ridges from the primitive yolk sac, resulting in spinal teratoma formation. ${ }^{[7]}$ In our situation, there is enough evidence to support the rationale of this theory, since we found that only $16 \%$ of adult cases were associated with spinal dysraphism ${ }^{[16,21,26]}$ and that the lower thoracic vertebrae and the conus medullaris region, which are adjacent to the caudal cell mass, represent the most common locations in adult population.

The alternative explanation comes from the dysembryogenic theory. This theory indicates that spinal teratomas arise from pluripotent cells which, in a locally disturbed developmental environment like a primitive streak or a caudal cell mass, differentiate chaotically, and create spinal teratoma. ${ }^{[33]}$ The dysraphic malformations and the occurrence of a neurenteric cyst without dysraphism $^{[34]}$ support this theory, and the tridermal anomaly, under such considerations, represents the primary event that will further affect the spinal closure. ${ }^{[33]}$

The indications for surgery in an adult with intraspinal mature teratoma are controversial. Radical resection should be the goal in symptomatic cases with radicular pain and/or progressive signs due to mass effect or cord tethering. ${ }^{[17]}$ On the other hand, asymptomatic patients and those having longstanding minor and stable neurological deficits may be treated conservatively, because prophylactic surgery can be associated with a high surgical risk in adult patients with no growing or very slow-growing lesions.

Some authors advise the removal of the capsule as a potential source of regrowth. ${ }^{[35]}$ However, an epidemiological study guided by Allsopp et al. ${ }^{[36]}$ showed that recurrence rates for complete and gross resection 
were extremely similar ( $9 \%$ and $11 \%$, respectively). Many authors no longer recommend radical resection as a preferred management policy for all cases, ${ }^{[19,20]}$ since the rate of adherence to the cord reaches $50 \%$ in this region, and any attempt at total resection may result in inadvertent damage to the conus. ${ }^{[10]}$ In the present case, complete resection was not feasible without potential injury of the conus medullaris, so it was judged safer to realize a gross total resection in order to preserve nerve integrity.

Due to the extremely low incidence of adult mature spinal teratoma and limited knowledge of this disease, there is little evidence to support the use of adjunctive therapies. $^{[36]}$ Radiation therapy is not justified since mature teratomas are benign tumors, and the efficacy of chemotherapy has not been demonstrated. ${ }^{[36]}$ Given the slow-growing nature of these tumors, patients will require serial clinical and radiological follow-up examinations for several years. Tumor markers such as B human chorionic hormone and alpha fetoproteinare of little interest in the follow-up of patients operated for mature intraspinal teratomas since a recurrence can take place from nonsecreting parts of the tumor. ${ }^{[36]}$

In conclusion, mature intradural teratomas in adults are rare, with few accompanying spinal anomalies. Their location in the conus medullaris is exceptional and can present with sciatica. Although complete resection is the primary goal, subtotal removal can be considered as a safe and effective option to manage these lesions, with the understanding that a small number of these patients may need reoperation. Long-term follow-up is mandatory.

\section{References}

1. Fernández-Cornejo VJ, Martínez-Pérez M, Polo-García LA, Martínez-Lage JF, Poza M. Cystic mature teratoma of the filum terminale in an adult. Case report and review of the literature. Neurocirugia (Astur) 2004;15:290-3.

2. Kubie LS, Fulton JF. A Clinical and Pathological Study of Two Teratomatous Cysts of the Spinal Cord, Containing Mucous and Ciliated Cells. Chicago: R.R. Donnelley; 1928. p. 42.

3. Hosoi K. Multiple neurofibromatosis (von Recklinghausen's disease) with special reference to malignant transformation. Arch Surg 1931;22:258-81.

4. Sullivan BH. Intraspinal teratoma, with report of a case. Brooklyn Hosp J 1948;6:142-5.

5. Case Reports of the Massachusetts General Hospital; weekly clinicopathological exercises: case 42502. $N$ Engl J Med 1956;255:1153-7.

6. Sloof JL, Kernohan JW, McCarty CS. Primary Intramedullary Tumors of the Spinal Cord and Filumterminale. Philadelphia: WB Saunders; 1964. p. 134.

7. Rewcastle NB, Francoeur J. Teratomatous cysts of the spinal canal; with "sex chromatin" studies. Arch Neurol 1964;11:91-9.

8. Hansebout RR, Bertrand G. Intraspinalteratoma simulating protruded intervertebral disc. J Neurosurg 1965;22:374-9.

9. Eneström S, Von Essen C. Spinal teratoma. Acta Neurochir 1977;39:121-6.

10. Rosenbaum TJ, Soule EH, Onofrio BM. Teratomatous cyst of the spinal canal. Case report. J Neurosurg 1978;49:292-7.
11. Garrison JE, Kasdon DL. Intramedullary spinal teratoma: case report and review of the literature. Neurosurgery 1980;7:509-12.

12. Padovani R, Tognetti F, Laudadio S, Manetto V. Teratoid cyst of the spinal cord. Neurosurgery 1983;13:74-7.

13. Pelissou-Guyotat I, Sindou M, Pialat J, Goutelle A. Intramedullary mature teratoma associated with an attached cord and an intradural lipoma. Apropos of a surgically treated case. Review of the literature. Neurochirurgie 1988;34:205-9.

14. Nicoletti GF, Passanisi M, Platania N, Lanzafame S, Albanese V. Intramedullary spinal cystic teratoma of the conusmedullaris with caudal exophytic development: case report. Surg Neurol 1994;41:106-11.

15. Caruso R, Antonelli M, Cervoni L, Salvati M. Intramedullary teratoma: case report and review of the literature. Tumori 1996;82:616-20.

16. al-Sarraj ST, Parmar D, Dean AF, Phookun G, Bridges LR. Clinicopathological study of seven cases of spinal cord teratoma: a possible germ cell origin. Histopathology 1998;32:51-6.

17. Poeze M, Herpers MJ, Tjandra B, Freling G, Beuls EA. Intramedullary spinal teratoma presenting with urinary retention: case report and review of the literature. Neurosurgery 1999;45:379-85.

18. Fan X, Turner JE, Turner TM, Elrod JP, Clough JA, Howell EI, Johnson MD. Carcinoid tumor development in an intramedullary spinal cord mature teratoma. AJNR $\mathrm{Am} J$ Neuroradiol 2001;22:1778-81.

19. Nonomura Y, Miyamoto K, Wada E, Hosoe H, Nishimoto H, Ogura H, Shimizu K. Intramedullary teratoma of the spine: report of two adult cases. Spinal Cord 2002;40:40-3.

20. Hejazi N, Witzmann A. Spinal intramedullary teratoma with exophytic components: report of two cases and review of the literature. Neurosurg Rev 2003;26:113-6.

21. Ak H, Ulu MO, Sar M, Albayram S, Aydin S, Uzan M. Adult intramedullary mature teratoma of the spinal cord: review of the literature illustrated with an unusual example. Acta Neurochir (Wien) 2006;148:663-9.

22. Makary R, Wolfson D, Dasilva V, Mohammadi A, Shuja S. Intramedullary mature teratoma of the cervical spinal cord at C1-2 associated with occult spinal dysraphism in an adult Case report and review of the literature. J Neurosurg Spine 2007;6:579-84.

23. Biswas A, Puri T, Goyal S, Gupta R, Eesa M, Julka PK, Rath GK. Spinal intradural primary germ cell tumour-review of literature and case report. Acta Neurochir (Wien) 2009;151:277-84.

24. Ghostine S, Perry E, Vaynman S, Raghavan R, Tong KA, Samudrala S, Johnson JP, Colohan A. The rare case of an intramedullary cervical spinal cord teratoma in an elderly adult: case report and literature review. Spine (Phila Pa 1976) 2009;34:E973-8.

25. Ijiri K, Hida K, Yano S, Iwasaki Y. Huge intradural ossification caused by a mature spinal teratoma: case report. Neurosurgery 2009;64:1200-1.

26. Jian W, Ying W, Chao Y. Intramedullary spinal teratoma of the conusmedullaris: report of two cases. Acta Neurochir (Wien) 2010;152:553-4.

27. Musil J, Mrlian A, Duba M, Kren L, Smrcka M. Probably the oldest patient with the diagnosis of medullar conusteratoma. Bratisl Lek Listy 2011;112:357-9.

28. Li Y, Yang B, Song L, Yan D. Mature teratoma of the spinal cord in adults: An unusual case. Oncol Lett 2013;6:942-6.

29. Vanguardia MK, Honeybul S, Robbins P. Subtotal resection of an intradural mature teratoma in an adult presenting with difficulty initiating micturition. Surg Neurol Int 2014;5:23.

30. Bouaziz M, Haouam K, Laouar O, Lankar A. A case of 
cervical intraduralextramedullary mature cystic teratoma: diagnosis and management. Neurochirurgie 2011;57:88-91.

31. Kwinta B, Adamek D, Moskala M, Stachura K. Tumours and tumour-like lesions of the spinal canal and spine. A review of 185 consecutive cases with more detailed close-up on some chosen pathologies. Pol J Pathol 2001;62:50-9.

32. Russell DS, Rubinstein LJ. Pathology of tumours of the nervous system. 5th ed. Baltimore: Williams and Wilkins; 1989. p. 664-750.

33. Koen JL, McLendon RE, George TM. Intradural spinal teratoma: evidence for a dysembryogenic origin. Report of four cases. J Neurosurg 1998;89:844-51.

34. Paleologos TS, Thom M, Thomas DG. Spinal neurenteric cysts without associated malformations. Are they the same as those presenting in spinal dysraphism? Br J Neurosurg 2000;14:185-94.
35. Post KD, Bederson J, Perin N, Stein BM. Surgical management of spinal cord tumors and arteriovenous malformations. In: Schmidek HH, editor; Schimidek and Sweet Operative Neurosurgical Techniques. 4th ed. Philadelphia: WB Saunders; 2000. p. 1855-73.

36. Allsopp G, Sgouros S, Barber P, Walsh AR. Spinal teratoma: is there a place for adjuvant treatment? Two cases and a review of the literature. Br J Neurosurg 2000;14:482-8.

How to cite this article: Ben Nsir A, Hammouda KB, Said IB, Kassar AZ, Kchir N, Jemel H. Spinal intradural mature teratoma in an elderly patient. J Cancer Metastasis Treat 2015;1:106-10.

Received: 30-01-2015; Accepted: 15-05-2015.

Source of Support: Nil, Conflict of Interest: None declared. 